\title{
Left Ventricular Assist Device Implantation and Concomitant Dor Procedure: a Single Center Experience
}

\author{
Andreas Schaefer ${ }^{1 *}$, MD, MHBA; Yvonne Schneeberger ${ }^{1 *}$, MD, MHBA; Liesa Castro ${ }^{1}$, MD; Bjoern Sill', MD; Yousuf \\ Alassar', MD; Meike Rybczynski², MD; Markus J Barten'1, MD; Hanno Grahn², MD; Hermann Reichenspurner', MD, \\ PhD; Sebastian A Philipp ${ }^{3 * *}, M D ;$ Alexander M Bernhardt ${ }^{1 * *}, M D$
}

\begin{abstract}
Objective: Left ventricular assist device (LVAD) implantation with concomitant Dor plasty is only reported anecdotally. We herein aimed to describe our experience with LVAD and concomitant Dor procedures and describe long-term outcomes of this special subset of heart failure patients.

Methods: Between January/2010 and December/2018, 144 patients received LVAD therapy at our institution. Of those, five patients $(80 \%$ male, $60.4 \pm 7.2$ years) presented with an apical aneurysm and received concomitant Dor plasty. Apical aneurysms presented diameter between 75 and $98 \mathrm{~mm}$, with one impending rupture.

Results: Procedural success was achieved in all patients. No unplanned right ventricular assist device implantation occurred. Furthermore, no acute 30-day mortality was seen. In follow-up, one
\end{abstract}

patient was lost due to intentional disconnection of the driveline. One patient underwent heart transplantation on postoperative day 630. The remaining three patients are still on device with sufficient flow; pump thromboses were successfully managed by lysis therapy in one patient.

Conclusion: LVAD implantation with concomitant Dor procedure is feasible, safe, and occasionally performed in patients with ischemic cardiomyopathy. Major advantages are prevention of thromboembolism and facilitation of LVAD placement by improving pump stability and warranting midventricular, coaxial alignment of the inflow cannula. In long-term follow-up, no adverse event associated with Dor plasty was observed.

Keywords: Heart Transplantation. Heart Failure. Thrombosis. Thromboembolism. Aneurysm. Cardiomyopathies.

\section{INTRODUCTION}

Due to limited availability of donor organs for heart transplantation, implantation of intracorporal miniaturized left ventricular assist devices (LVAD) became clinical daily routine for treatment of end-stage heart failure (HF), with the number of procedures increasing annually ${ }^{[1,2]}$. HF remains the most common reason for hospital admission in the United States and Western Europe, and therefore, it can be anticipated that the number of LVAD implantations will further increase. Currently, $100 \%$ of patients in need for destination therapy, registered in the Interagency Registry for Mechanically Assisted Circulatory Support (INTERMACS), receive continuous-flow (CF) pumps ${ }^{[3,4]}$. These miniaturized CF pumps improve the outcome of patients with end-stage HF in terms of symptoms, hospitalization, and

'Department of Cardiovascular Surgery, University Heart and Vascular Center Hamburg, Hamburg, Germany.

2Department of General and Interventional Cardiology, University Heart and Vascular Center Hamburg, Hamburg, Germany.

${ }^{3}$ Department of Cardiology and Intensive Care Medicine, Elbe Clinic, Stade, Germany.

*AS and YS contributed equally to this work.

**AP and AMB contributed equally to this work. premature death while awaiting transplantation ${ }^{[5]}$. Patients selected for LVAD implantation usually suffer from significant comorbidities which may (e.g., renal failure and lung disease) or may not be associated with the underlying cardiac disease ${ }^{[6]}$. Especially concomitant cardiac conditions, like valve stenosis/ regurgitation, coronary heart disease, or right ventricular failure, require additional procedures during LVAD implantation. Here, outcomes were reported for concomitant valve repair/ replacement (aortic, mitral, tricuspid), patent foramen ovale closure, or implantation of a temporary right ventricular assist device $(\mathrm{RVAD})^{[7-9]}$. Another precondition which may be complicating to LVAD surgery is a left ventricular aneurysm in patients with ischemic cardiomyopathy (ICMP) and status post $(s / p)$ transmural myocardial infarction. Here, LVAD insertion is

Correspondence Address:

Andreas Schaefer

iD https://orcid.org/0000-0001-7304-6083

University Heart and Vascular Center Hamburg

Martinistraße 52, Hamburg, Germany

Zip Code: D-20246

E-mail: and.schaefer@uke.de 


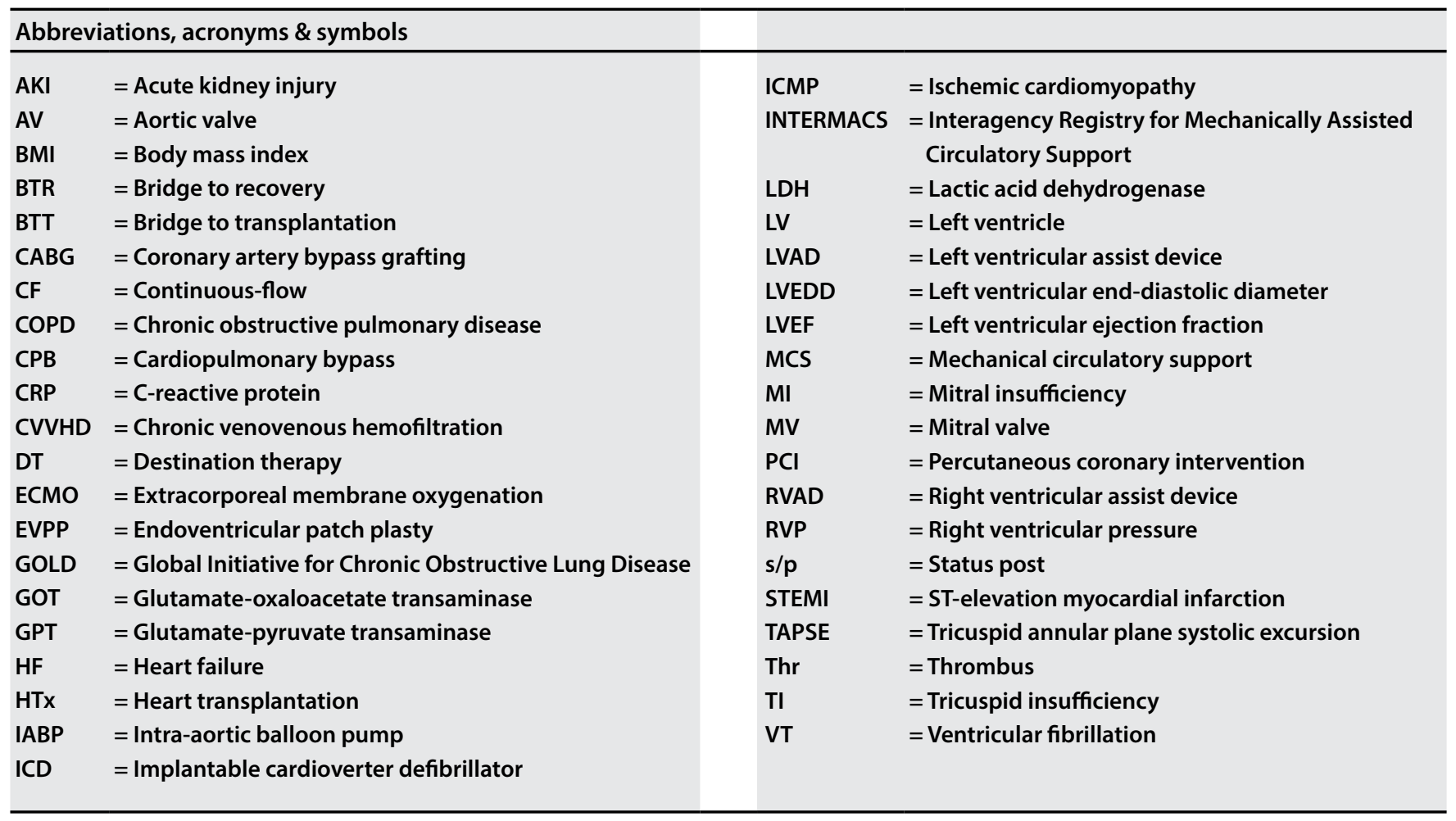

compounded by a thin apical myocardium, and left ventricular thrombus formation is often present ${ }^{[10]}$. To facilitate CF pump insertion and placement and to prevent thromboembolism in such cases, concomitant endoventricular patch plasty (EVPP) (Dor procedure ${ }^{[11]}$ ) should be taken into consideration. However, these combined procedures are only described anecdotally with documentation of acute and perioperative outcomes ${ }^{[12]}$. We herein describe our experience with combined LVAD and Dor procedures with an emphasis on long-term follow-up.

\section{METHODS}

\section{Patients}

Between January/2010 and December/2018, 144 patients received LVAD therapy for end-stage HF at our institution. Of those, five patients $(5 / 144,3.5 \%)$ presented with apical aneurysms and received concomitant Dor plasty during LVAD implantation. All five patients presented with ICMP, s/p ST-elevation myocardial infarction, and severely reduced left ventricular ejection fraction. Four patients had a history of multiple percutaneous coronary interventions and one patient underwent multiple coronary artery bypass grafting procedures.

\section{Ventricular Assist Device Implantation and Concomitant Endoventricular Patch Plasty}

In all patients, a HeartWare HVAD (Medtronic, Minneapolis, MN, USA) device was implanted through median sternotomy with support of cardiopulmonary bypass (CPB) to unload the left ventricle. After luxation of the heart, the left ventricular apex was opened. Subsequently, thrombotic material was removed, and the edge of vital myocardium was identified. Here, a reinforcing running 2-0 Prolene (Ethicon Inc., Somerville, NJ, USA) suture buttressed with Teflon felt was performed. Simultaneously, the HVAD ring was sewed in a Vascutek (Terumo Co., Shibuya, Tokyo, Japan) or pericardial patch utilizing a running 3-0 Prolene suture. Then, the patch was attached to the neoapex with interrupted felt-pleged 3-0 Prolene sutures and the patch was furthermore secured by a subsequent performed running 2-0 Prolene suture comprising transmural stitches of vital myocardium. Further procedural steps followed institutional routines including HVAD pump insertion and alignment, tunneling of the driveline, and attaching of the outflow graft to the ascending aorta. Crucial steps of the described procedure are depicted in Figure 1.

\section{Follow-Up}

Baseline, intraprocedural, and follow-up data were collected and entered into a dedicated standardized database. Clinical endpoints were death and heart transplantation. Mean followup time was 547.6 \pm 473.1 days. Data are presented as absolute numbers and percentages for categorical variables and mean values and standard deviation for continuous variables, unless stated otherwise.

\section{RESULTS}

\section{Baseline Demographics}

Overall, five patients (80\% male, 60.4 7.2 years) received concomitant EVPP during LVAD implantation for apical aneurysm 

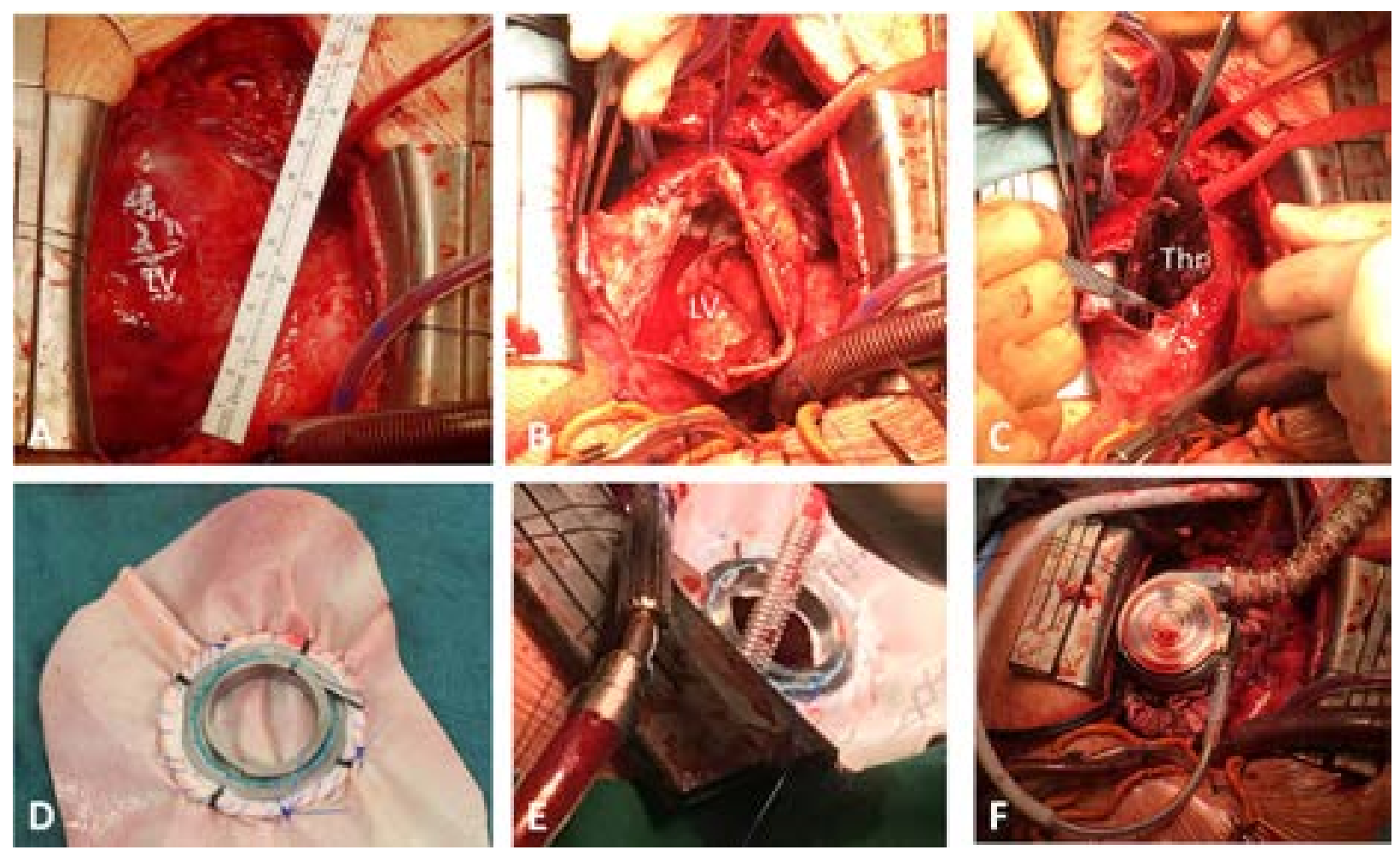

Fig. 1 - Intraoperative pictures of left ventricular assist device (LVAD) implantation with concomitant Dor plasty. Intraoperative course of patient n. 5: large left ventricular apex aneurysm after median sternotomy (A), opening of the apex (B) and removal of a large thrombus (Thr) $(C)$, adaptation of the LVAD sewing ring to a patch (D), apex reconstruction with the patch $(E)$, and implantation of the LVAD device $(F)$. LV=left ventricle

and end-stage HF at our institution. Of those, three patients (60\%) fulfilled clinical requirements for INTERMACS level 1 or 2, with one patient in need for preoperative temporary mechanical circulatory support (extracorporeal membrane oxygenation therapy). Two patients presented with INTERMACS levels 3 and 4. In three patients, LVAD implantation strategy was bridge to transplantation, and in two patients destination therapy.

Detailed baseline patient demographics are shown in Table 1.

\section{Preoperative Laboratory and Echocardiographic Findings}

Preoperatively, patients presented with moderate signs of end-organ damage in advanced HF with a mean creatinine value of $1.3 \pm 0.6 \mathrm{mg} / \mathrm{dl}$ and a glutamic oxaloacetic transaminase of $113.6 \pm 191.2 \mathrm{U} / \mathrm{l}$.

Echocardiography revealed a preoperative left ventricular ejection fraction of $16.2 \pm 5.1 \%$ and no precursors of impaired right ventricular function with a tricuspid annular plane systolic excursion of $17.0 \pm 4.5 \mathrm{~mm}$, a right ventricular pressure of $45.2 \pm 6.4$ $\mathrm{mmHg}$, and a tricuspid insufficiency $\geq$ moderate in only one patient $(1 / 5,20 \%)$.

Apical aneurysms presented with a diameter between 75 and $98 \mathrm{~mm}$, with left ventricular end-diastolic diameters between 44 and $70 \mathrm{~mm}$. One patient with an apical aneurysm of $98 \mathrm{~mm}$ presented an extremely thin myocardial wall of the left ventricular apex in preoperative echocardiography, and
LVAD implantation with concomitant EVPP was performed as an emergency procedure due to risk of rupture.

Representative preoperative echocardiographic images of apical aneurysms are shown in Figure 2.

Detailed preoperative laboratory and echocardiographic findings are summarized in Table 2.

\section{Periprocedural Data}

Mean operation time was $343.0 \pm 67.5$ min with use of CPB in all cases, with a mean time of $208.0 \pm 60.8 \mathrm{~min}$. Cross-clamping of the ascending aorta was performed in one patient. In no case concomitant valve procedures were performed. Also, no planned or unplanned implantation of temporary RVAD was necessary. In all patients, intraoperative echocardiography presented midventricular and coaxial alignment of the LVAD inflow cannula at the end of the procedure.

\section{Clinical Outcome Data}

LVAD implantation success and 30-day survival were 100\% (5/5) with no pump thrombosis or major bleedings (including rethoracotomies) in acute follow-up. In two patients, dilative tracheostomy was performed due to respiratory failure with ventilation times of 232 and 790 hours. Both patients were weaned successfully from mechanical ventilation. Chronic venovenous hemofiltration with a duration of 30 days was 
Table 1. Baseline characteristics of patients who underwent LVAD implantation with concomitant Dor plasty.

\begin{tabular}{|c|c|c|c|c|c|c|}
\hline & \multicolumn{6}{|c|}{ Patient No. } \\
\hline & 1 & 2 & 3 & 4 & 5 & $\Sigma$ \\
\hline Age, years & 66 & 49 & 61 & 67 & 59 & $60.4 \pm 7.2$ \\
\hline Gender, male/female & Female & Male & Male & Male & Male & 4/5 male \\
\hline $\mathrm{BMl}, \mathrm{kg} / \mathrm{m}^{2}$ & 26.7 & 21.6 & 28.9 & 22.3 & 24.1 & $24.7 \pm 3.1$ \\
\hline INTERMACS profile & 2 & 1 & 3 & 2 & 4 & 1 \\
\hline Strategy for LVAD implantation, $\boldsymbol{V} / \boldsymbol{x}$ & & & & & & 1 \\
\hline BTT & $x$ & $\checkmark$ & $\checkmark$ & $x$ & $\checkmark$ & I \\
\hline DT & $\checkmark$ & $x$ & $x$ & $\checkmark$ & $x$ & 1 \\
\hline BTR & $x$ & $x$ & $x$ & $x$ & $x$ & 1 \\
\hline Preoperative mechanical ventilation, $\boldsymbol{V} / \mathbf{x}$ & $x$ & $\checkmark$ & $x$ & $x$ & $x$ & 1 \\
\hline Preoperative MCS (ECMO, IABP, Impella) & $x$ & ECMO & $x$ & $x$ & $x$ & I \\
\hline Further diagnosis & $\begin{array}{l}\text { s/p STEMI, s/p } \\
\text { PCI, COPD, } \\
\text { GOLD IV, s/p } \\
\text { breast cancer }\end{array}$ & $\begin{array}{c}\text { s/p STEMI, s/p } \\
\text { PCl, s/p stroke, } \\
\text { diabetes } \\
\text { mellitus }\end{array}$ & $\begin{array}{l}\text { s/p STEMI, s/p } \\
\text { CABG, re-CABG, } \\
\text { re-re-CABG, s/p } \\
\mathrm{PCl}, \mathrm{s} / \mathrm{p} \text { stroke }\end{array}$ & $\begin{array}{c}\text { s/p STEMI, s/p } \\
\mathrm{PCl}, \mathrm{s} / \mathrm{p} \text { dilative } \\
\text { tracheostomy, s/p } \\
\text { alcohol abuse }\end{array}$ & $\begin{array}{l}\text { s/p STEMI, } \\
\text { s/p PCl }\end{array}$ & / \\
\hline
\end{tabular}

$\mathrm{BMI}=$ body mass index; $\mathrm{BTR}=$ bridge to recovery; $\mathrm{BTT}=$ bridge to transplantation; $\mathrm{CABG}=$ coronary artery bypass grafting; $\mathrm{COPD}=\mathrm{chronic}$ obstructive pulmonary disease; $\mathrm{DT}=$ destination therapy; $\mathrm{ECMO}=$ extracorporeal membrane oxygenation; GOLD=Global Initiative for Chronic Obstructive Lung Disease; IABP=intra-aortic balloon pump; INTERMACS=Interagency Registry for Mechanically Assisted Circulatory Support; LVAD=left ventricular assist device; $M C S=$ mechanical circulatory support; $P C l=$ percutaneous coronary intervention; $\mathrm{s} / \mathrm{p}=$ status=post; STEMI=ST-elevation myocardial infarction
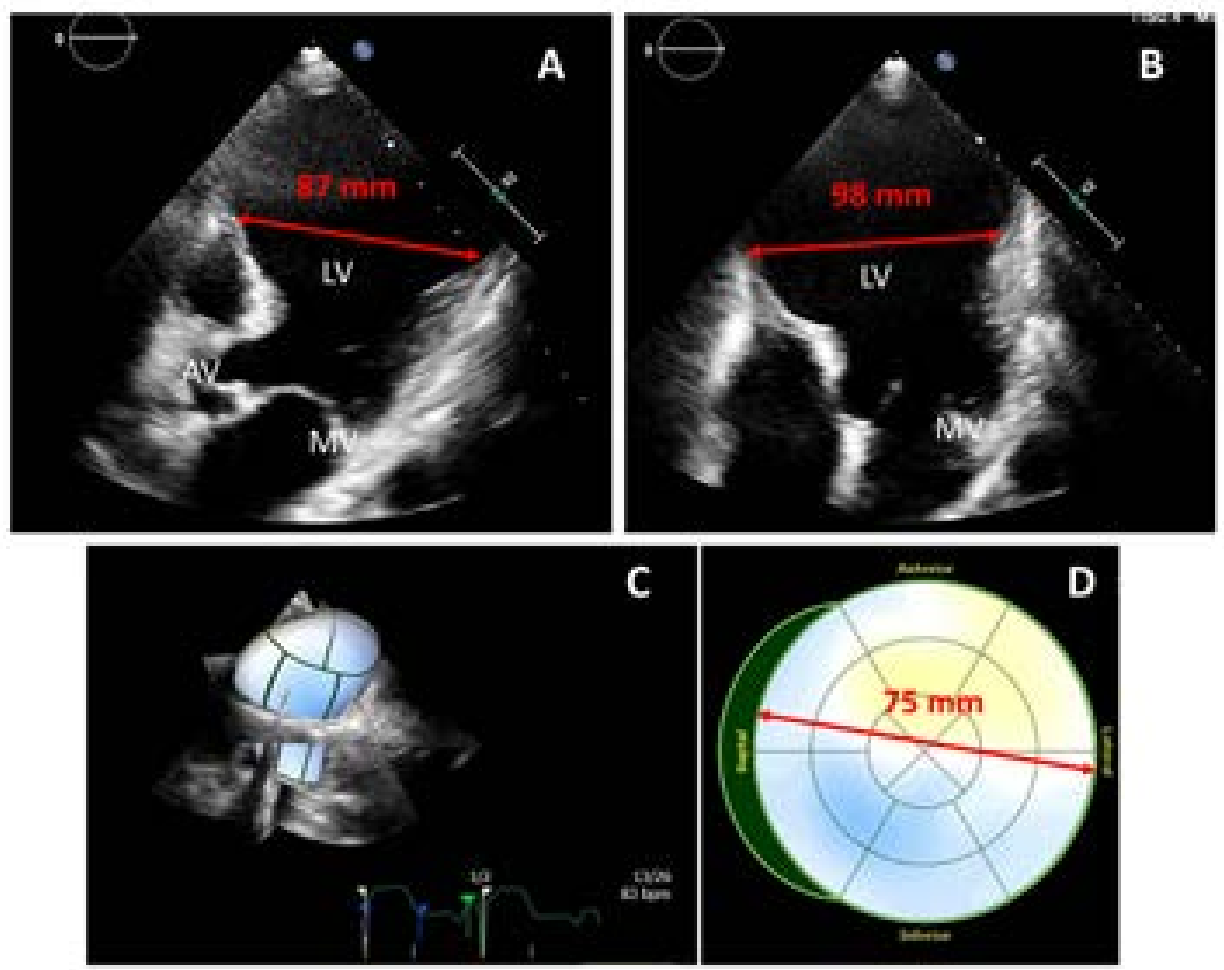

Fig. 2 - Preoperative transthoracic echocardiography with depiction of large left ventricular apex aneurysms in patients prior to left ventricular assist device implantation with concomitant Dor plasty. Five-chamber view of patient $n$. 1 with a left ventricular apex aneurysm of $87 \mathrm{~mm}$ (A), fourchamber view of patient $n .5$ with a left ventricular apex aneurysm of $98 \mathrm{~mm}$ and impending rupture (B), and $3 D$ left ventricular apex reconstruction of patient $n$. 4 with a septolateral diameter of $75 \mathrm{~mm}(C, D)$. $A V=$ aortic valve; $L V=l e f t$ ventricle; $M V=$ mitral valve 
Table 2. Periprocedural laboratory, echocardiographic, and intraoperative characteristics of patients who underwent LVAD implantation with concomitant Dor plasty.

\begin{tabular}{|c|c|c|c|c|c|c|}
\hline & \multicolumn{6}{|c|}{ Patient No. } \\
\hline & 1 & 2 & 3 & 4 & 5 & $\Sigma$ \\
\hline \multicolumn{7}{|l|}{ Laboratory } \\
\hline Creatinine, mg/dl & 0.9 & 2.0 & 0.9 & 1.8 & 0.8 & $1.3 \pm 0.6$ \\
\hline Hemoglobin, g/dl & 9.2 & 9.1 & 10.9 & 13.9 & 10.6 & $10.7 \pm 1.9$ \\
\hline $\mathrm{GOT}, \mathrm{U} / \mathrm{I}$ & 13 & 44 & 29 & 455 & 27 & $113.6 \pm 191.2$ \\
\hline GPT, U/I & 20 & 34 & 47 & 80 & 63 & $48.8 \pm 23.6$ \\
\hline Lactate, mmol// & 1.5 & 2.4 & 2.1 & 2.8 & 1.1 & $1.9 \pm 0.7$ \\
\hline CRP, mg/l & 5 & 82 & 9 & 47 & 24 & $33.4 \pm 31.8$ \\
\hline $\mathrm{LDH}, \mathrm{U} / \mathrm{I}$ & 165 & 235 & 226 & 123 & 319 & $213.6 \pm 74.7$ \\
\hline \multicolumn{7}{|l|}{ Echocardiography } \\
\hline LVEF, \% & 15 & 12 & 25 & 14 & 15 & $16.2 \pm 5.1$ \\
\hline LVEDD, mm & 66 & 70 & 64 & 68 & 44 & $62.4 \pm 10.5$ \\
\hline Apical aneurysm diameter, mm & 87 & 98 & 77 & 75 & $\begin{array}{l}\text { 98, impending } \\
\text { rupture }\end{array}$ & $84.3 \pm 10.6$ \\
\hline $\mathrm{Ml} \geq$ grade $2, \boldsymbol{V} / \boldsymbol{x}$ & $x$ & $\checkmark$ & $x$ & $x$ & $x$ & / \\
\hline $\mathrm{TI} \geq$ grade $2, \boldsymbol{V} / \boldsymbol{x}$ & $x$ & $x$ & $x$ & $x$ & $\boldsymbol{V}$ & / \\
\hline $\mathrm{RVP}, \mathrm{mmHg}$ & 47 & 55 & 44 & 42 & 38 & $45.2 \pm 6.4$ \\
\hline TAPSE, mm & 23 & 12 & 16 & 20 & 14 & $17.0 \pm 4.5$ \\
\hline Procedure time, min & 305 & 335 & 380 & 260 & 435 & $343.0 \pm 67.5$ \\
\hline CPB time, min & 180 & 195 & 302 & 139 & 224 & $208.0 \pm 60.8$ \\
\hline Cross-clamp time, min & 0 & 120 & 0 & 0 & 0 & / \\
\hline Need for temporary RVAD, $\boldsymbol{V} / \mathbf{X}$ & $x$ & $x$ & $x$ & $x$ & $x$ & $0 / 5 \boldsymbol{\sim}$ \\
\hline
\end{tabular}

$\mathrm{CPB}=$ cardiopulmonary bypass; $\mathrm{CRP}=\mathrm{C}$-reactive protein; $\mathrm{GOT}=$ glutamate-oxaloacetate transaminase; GPT=glutamate-pyruvate transaminase; $\mathrm{LDH}=$ Lactic acid dehydrogenase; LVAD=left ventricular assist device; LVEDD=left ventricular end-diastolic diameter; $\mathrm{LVEF}=$ left ventricular ejection fraction; $\mathrm{Ml}=$ mitral insufficiency; RVAD=right ventricular assist device; $\mathrm{RVP}=$ right ventricular pressure; TAPSE=tricuspid annular plane systolic excursion; TI=tricuspid insufficiency

necessary in one patient with a preoperative creatinine of 2.0 $\mathrm{mg} / \mathrm{dl}$.

In long-term follow-up, one patient was lost on postoperative day 98 due to intentional disconnection of the driveline by the patient. One patient underwent orthotopic heart transplantation on postoperative day 630. Three patients are still on device, with gastrointestinal bleedings in two patients. Moreover, one acute kidney injury occurred during follow-up and one patient presented three consecutive pump thromboses, which were successfully managed by lysis therapy. Quarterly performed echocardiography presented stable, coaxial, and midventricular position of the inflow cannula in all patients. Also, flow and revolutions per minute measurements showed steady values.

Detailed outcome data are summarized in Table 3.

\section{DISCUSSION}

The main findings of the herein conducted study are: (I) LVAD implantation with concomitant Dor procedure is feasible, safe, and occasionally performed in patients with ICMP, (II) no adverse events associated with additional EVPP during LVAD implantation were found in acute or long-term follow-up, (III) once midventricular and coaxial alignment of the inflow cannula is achieved by implantation of the LVAD into the neoapex, pump position is maintained as suggested by our quarterly performed echocardiography, and (IV) prolongation of procedure and CPB time is acceptable in our presented cases and these combined procedures can be performed without cross-clamping in most patients. 
Table 3. Acute outcomes and follow-up of patients who underwent LVAD implantation with concomitant Dor plasty.

\begin{tabular}{|c|c|c|c|c|c|c|}
\hline & \multicolumn{6}{|c|}{ Patient No. } \\
\hline & 1 & 2 & 3 & 4 & 5 & $\Sigma$ \\
\hline LVAD implantation success, $\boldsymbol{V} / \boldsymbol{x}$ & $\checkmark$ & $\checkmark$ & $\checkmark$ & $\checkmark$ & $\boldsymbol{V}$ & $5 / 5 \boldsymbol{V}$ \\
\hline \multicolumn{7}{|l|}{ 30-day follow-up, LVAD, $\boldsymbol{V} / \boldsymbol{x}$} \\
\hline Pump thrombosis & $x$ & $x$ & $x$ & $x$ & $x$ & $0 / 5 \checkmark$ \\
\hline Major bleeding & $x$ & $x$ & $x$ & $x$ & $x$ & $0 / 5 \boldsymbol{v}$ \\
\hline Dilative tracheostomy & $x$ & $x$ & $\checkmark$ & $\checkmark$ & $x$ & $2 / 5 \boldsymbol{v}$ \\
\hline Ventilation time, hours & 9 & 18 & 232 & 790 & 2 & $210.2 \pm 338.2$ \\
\hline CVVHD & $x$ & $\boldsymbol{V}$ & $x$ & $x$ & $x$ & $1 / 5 \checkmark$ \\
\hline Duration of CVVHD, days & / & 30 & / & / & / & I \\
\hline 30-day survival, $\boldsymbol{V} / \boldsymbol{x}$ & $\checkmark$ & $\checkmark$ & $\checkmark$ & $\checkmark$ & $\checkmark$ & $5 / 5 \boldsymbol{v}$ \\
\hline Follow-up time, days & 540 & 630 & 1290 & 98 & 180 & $547.6 \pm 473.1$ \\
\hline Outcome at follow-up & Alive, on LVAD & Alive, s/p HTx & Alive, on LVAD & Deceased & Alive, on LVAD & 1 \\
\hline Complications during follow-up & $\begin{array}{c}\text { AKI, } \\
\text { gastrointestinal } \\
\text { bleeding }\end{array}$ & $\begin{array}{c}\text { Epistaxis, } \\
\text { VF, ICD } \\
\text { implantation }\end{array}$ & $\begin{array}{c}\text { Gastrointestinal } \\
\text { bleeding, } \\
\text { 3'pump } \\
\text { thrombosis }\end{array}$ & $\begin{array}{c}\text { Intentional } \\
\text { disconnection } \\
\text { of driveline }\end{array}$ & / & / \\
\hline
\end{tabular}

$\mathrm{AKI}=$ acute kidney injury; $\mathrm{CVVHD}=$ chronic venovenous hemofiltration; $H \mathrm{Tx}=$ heart transplantation; ICD=implantable cardioverter defibrillator; LVAD=left ventricular assist device; $V T=$ entricular fibrillation

Major advantages of a concomitant EVPP during LVAD implantation were already described ${ }^{[12-14]}$. Despite different reported techniques, prevention of thromboembolism by removal of thrombotic material from the former apex and more stable placement of the pump with coaxial and midventricular positioning of the inflow cannula towards the mitral valve are considered to be facilitated by EVPP. The herein described experience confirms these assumptions. Especially in preposterous dilated aneurysms (like the herein described 98 $\mathrm{mm}$ aneurysm with impending rupture) of the left ventricular apex, placement of an LVAD pump is not feasible. With the described technique including excision of thin myocardial wall, identification of vital myocardium, and removal of thrombotic material, shaping of an adequate neoapex for stable pump placement was feasible in all patients. Durability of this solution is of special importance in this scenario and preserved cannula position was confirmed in all patients during echocardiographic follow-up examinations. However, larger patient cohorts are needed before general recommendations regarding EVPP techniques can be made. Also, removal of thrombotic material was effective in the herein described patient cohort. Despite omission of cross-clamping in $80 \%$ of the patients, no strokes or pump failure occurred during follow-up. One patient presented with recurrent episodes of pump thromboses, which were treated by lysis therapy and are most likely not connected to preexisting thrombotic material in the left ventricle, since the first pump thrombosis occurred on postoperative day 560. The patient is now event free for 370 days. In the herein reported follow-up, so far the longest for these combined procedures, no events were seen connected to EVPP, which is further corroborating the safety and feasibility of the LVAD and EVPP approach in the instance of left ventricular apical aneurysm. Documented events were mainly bleeding and renal and respiratory failures. These complications were described extensively for patients with end-stage HF undergoing LVAD implantation ${ }^{[15,16]}$ and are not attributable to the performed Dor plasty.

\section{CONCLUSION}

In conclusion, LVAD implantation with concomitant EVPP procedural is safe and feasible in patients with end-stage HF, ICMP, and apical aneurysms, facilitates pump placement by building a stable neoapex, and does not affect outcomes in terms of occurrence of acute and long-term events. These findings have to be confirmed in larger patient cohorts before general recommendations can be made.

\section{No financial support. \\ No conflict of interest.}

\section{REFERENCES}

1. Kirklin JK, Naftel DC, Pagani FD, Kormos RL, Stevenson LW, Blume ED, et al. Seventh INTERMACS annual report: 15,000 patients and counting. J Heart Lung Transplant. 2015;34(12):1495-504. doi:10.1016/j. healun.2015.10.003. 
2. Kirklin JK, Pagani FD, Kormos RL, Stevenson LW, Blume ED, Myers SL, et al. Eighth annual INTERMACS report: special focus on framing the impact of adverse events. J Heart Lung Transplant. 2017;36(10):1080-6. doi:10.1016/j.healun.2017.07.005.

3. Sperry BW, Ruiz G, Najjar SS. Hospital readmission in heart failure, a novel analysis of a longstanding problem. Heart Fail Rev. 2015;20(3):251-8. doi:10.1007/s10741-014-9459-2.

4. Guha K, McDonagh T. Heart failure epidemiology: European perspective. Curr Cardiol Rev. 2013;9(2):123-7. doi:10.2174/1573403×11309020005.

5. McMurray JJ, Adamopoulos S, Anker SD, Auricchio A, Böhm M, Dickstein $K$, et al. ESC guidelines for the diagnosis and treatment of acute and chronic heart failure 2012: the task force for the diagnosis and treatment of acute and chronic heart failure 2012 of the European society of cardiology. Eur J Heart Fail. 2012;14(8):803-69. Erratum in: Eur J Heart Fail. 2013;15(3):361-2. doi:10.1093/eurjhf/hfs105.

6. Gustafsson F, Rogers JG. Left ventricular assist device therapy in advanced heart failure: patient selection and outcomes. Eur J Heart Fail. 2017;19(5):595-602. doi:10.1002/ejhf.779.

7. Morgan JA, Tsiouris A, Nemeh HW, Hodari A, Karam J, Brewer RJ, et al. Impact of concomitant cardiac procedures performed during implantation of long-term left ventricular assist devices. J Heart Lung Transplant. 2013;32(12):1255-61. doi:10.1016/j.healun.2013.09.009.

8. John R, Naka Y, Park SJ, Sai-Sudhakar C, Salerno C, Sundareswaran KS, et al. Impact of concurrent surgical valve procedures in patients receiving continuous-flow devices. J Thorac Cardiovasc Surg. 2014;147(2):581-9; discussion 589. doi:10.1016/j.jtcvs.2013.10.024

9. Schaefer A, Reichart D, Bernhardt AM, Kubik M, Barten MJ, Wagner FM, et al. Outcomes of minimally invasive temporary right ventricular assist device support for acute right ventricular failure during minimally invasive left ventricular assist device implantation. ASAIO J. 2017;63(5):546-50. doi:10.1097/MAT.0000000000000526.

10. You J, Wang X, Wu J, Gao L, Wang X, Du P, et al. Predictors and prognosis of left ventricular thrombus in post-myocardial infarction patients with left ventricular dysfunction after percutaneous coronary intervention. J Thorac Dis. 2018;10(8):4912-22. doi:10.21037/jtd.2018.07.69.

11. Dor V, Saab M, Coste P, Kornaszewska M, Montiglio F. Left ventricular aneurysm: a new surgical approach. Thorac Cardiovasc Surg. 1989;37(1):11-9. doi:10.1055/s-2007-1013899.

12. Altas O, Ozer T, Ozgur MM, Sarikaya S, Kirali K. Regenerating a ventricular cavity during left ventricular assist device implantation. J Artif Organs. 2019;22(2):169-72. doi:10.1007/s10047-019-01089-4.

13. Fatullayev J, Butters T, Sabashnikov A, Garcia Saez D, Mohite PN, Edwards $\mathrm{G}$, et al. Left ventricular assist device implantation with concomitant left ventricular reconstruction without patchplasty. J Artif Organs. 2014;17(4):370-2. doi:10.1007/s10047-014-0785-x.

14. Chernyavskiy AM, Marchenko AV, Lomivorotov VV, Doronin D, Alsov SA, Nesmachnyy A. Left ventricular assist device implantation combined with surgical ventricular reconstruction. Tex Heart Inst J. 2012;39(5):627-9.

15. Braun OÖ, Nilsson J, Gustafsson F, Dellgren G, Fiane AE, Lemström K, et al. Continuous-flow LVADs in the Nordic countries: complications and mortality and its predictors. Scand Cardiovasc J. 2019;53(1):14-20. doi:10.1080/14017431.2019.1583365.

16. Tripathi B, Arora S, Kumar V, Thakur K, Lahewala S, Patel N, et al. Hospital complications and causes of 90-day readmissions after implantation of left ventricular assist devices. Am J Cardiol. 2018;122(3):420-30. doi:10.1016/j.amjcard.2018.04.015.

\section{Authors' roles \& responsibilities}

AS

Substantial contributions to the conception or design of the work; or the acquisition, analysis, or interpretation of data for the work; drafting the work or revising it critically for important intellectual content; final approval of the version to be published

YS Substantial contributions to the conception or design of the work; or the acquisition, analysis, or interpretation of data for the work; drafting the work or revising it critically for important intellectual content; final approval of the version to be published

LC Substantial contributions to the conception or design of the work; or the acquisition, analysis, or interpretation of data for the work; drafting the work or revising it critically for important intellectual content; final approval of the version to be published

BS Substantial contributions to the conception or design of the work; or the acquisition, analysis, or interpretation of data for the work; drafting the work or revising it critically for important intellectual content; final approval of the version to be published

YA Substantial contributions to the conception or design of the work; or the acquisition, analysis, or interpretation of data for the work; drafting the work or revising it critically for important intellectual content; final approval of the version to be published

MR Substantial contributions to the conception or design of the work; or the acquisition, analysis, or interpretation of data for the work; drafting the work or revising it critically for important intellectual content; final approval of the version to be published

MJB Substantial contributions to the conception or design of the work; or the acquisition, analysis, or interpretation of data for the work; drafting the work or revising it critically for important intellectual content; final approval of the version to be published

HG Substantial contributions to the conception or design of the work; or the acquisition, analysis, or interpretation of data for the work; drafting the work or revising it critically for important intellectual content; final approval of the version to be published

HR Substantial contributions to the conception or design of the work; or the acquisition, analysis, or interpretation of data for the work; drafting the work or revising it critically for important intellectual content; final approval of the version to be published

SAP Substantial contributions to the conception or design of the work; or the acquisition, analysis, or interpretation of data for the work; drafting the work or revising it critically for important intellectual content; final approval of the version to be published

AMB Substantial contributions to the conception or design of the work; or the acquisition, analysis, or interpretation of data for the work; drafting the work or revising it critically for important intellectual content; final approval of the version to be published 